Case Report

\title{
Isodense Acute Epidural Hematoma in an Anemic Patient - Diagnostic and Therapeutic Trap: A Case Report
}

\author{
Sajid Khan', Musawer Khan², Naeem-ul-Haq², Mumtaz Ali ${ }^{1}$, Muhammad Ishaq ${ }^{2}$ \\ ${ }^{1}$ Department of Neurosurgery, Prime Teaching Hospital, Warsak Road, Peshawar \\ ${ }^{2}$ Mardan Medical Complex, Mardan, KPK - Pakistan
}

\begin{abstract}
Post-traumatic acute epidural and subdural hematoma is a common neurosurgical emergency. Epidural or extradural hematoma is an accumulation of blood between the skull and dura mater, mostly appears asa hyperdense biconvex shape on computed tomography (CT) scan. In our present study, weencountered a case of an eight years old malechild brought to the hospital with head trauma in aroad traffic accident. Initial CT scan revealed an epidural hematoma, which appeared isodense rather than the usual hyperdense presentation. This unusual presentation was due to low hematocrit (HCT). Thisparticular presentation poses a diagnostic dilemma and can compromise patient managementultimately leading to treatment failure. Here, we present a case report about diagnosing and managing an anemic patient with traumatic isodense acute epidural hematoma.
\end{abstract}

Keywords: Head trauma, acute epidural hematoma, Hematocrit, Anemia, CT scan.

Key Messages: An unusual isodense acute epidural hematoma in an anemic patient can lead to higher chances of misdiagnosis and ultimately incorrect management choices.

Abbreviations: HCT: Hematocrit. CT: Computed Tomography Scan. CSF: Cerebro-spinal fluid. GCS: Glasgow Coma Scale.

\section{Corresponding Author: \\ Musawer Khan \\ Department of Neurosurgery \\ Mardan Medical Complex, Mardan \\ Email: modestgaze@yahoo.com \\ Date of Submission: 28-08-2021 \\ Date of Revision: 16-09-2021 \\ Date of Acceptance: 20-09-2021 \\ Date of Online Publishing: 30-09-2021 \\ Date of Print: 30-09-2021}

DOI: 10.36552/pjns.v25i3.598

\section{INTRODUCTION}

Traumatic brain injuries are commonly presented with road traffic accidents causing a subdural or epidural hematoma. Epidural hematoma (also called an extradural hematoma) is an accumulation of blood between the inside of the skull surface and outside dura mater putting pressure on the brain leading to lifelong disability or death. ${ }^{1,2}$ Brain CT scan is the most commonly used diagnostic tool for a head injury. Generally, acute epidural hematoma appears hyperdense, 
biconvex mass lesion on CT scan. $^{3}$ But unexpectedly few cases have been reported in neurosurgical literature with acute isodense subdural and epidural hematomas. ${ }^{4}$ Different radiological presentation of the same pathology is possibly due to decreased hematocrit level or mixing of CSF (Cerebro-spinal fluid) with blood due to dural laceration. ${ }^{4}$

We report a case with atypical presentation of isodense acute epidural hematoma which can be a cause of misdiagnosis, leading to medical errors.

\section{CASE HISTORY}

An 8-year-old male child was admitted to neurotrauma after a road traffic accident with epidural hematoma which appeared isodense on CT scan brain rather than usual hyperdense presentation. An initial medical examination showed that patient was vitally stable with normal respiration and no associated injuries. On neurological examination, his Glasgow Coma Scale (GCS) was 10/15 with dilated right pupil, sluggish to react. Whilethe left pupillary responsewas found normal. There were no signs of skull base fracture. However, subgaleal swelling was appreciated in the right temporoparietal region. No associated injuries or long bones fractures were reported.

Noncontrast CT brain was performed after 3 hours of head trauma, showing right-sided isodense biconvex shaped lesion with hyperdense peripheries measuring $18 \times 12 \times 13$ with linear fracture of parietal bone and subgaleal collection with $3 \mathrm{~mm}$ midline shift (Figure 1 and Figure 2).

The patient was admitted and baseline investigations were done. Initial laboratory reports revealed anemia with $\mathrm{Hb} 8 \mathrm{~g}^{\mathrm{dl}}{ }^{-1}$ and $\mathrm{HCT}$ of $26 \%$, other investigations were normal. Blood transfusion started and packed RBCs were arranged. One unit of packed red blood cells was administered. The patient was immediately shifted to the operating theater. During surgery

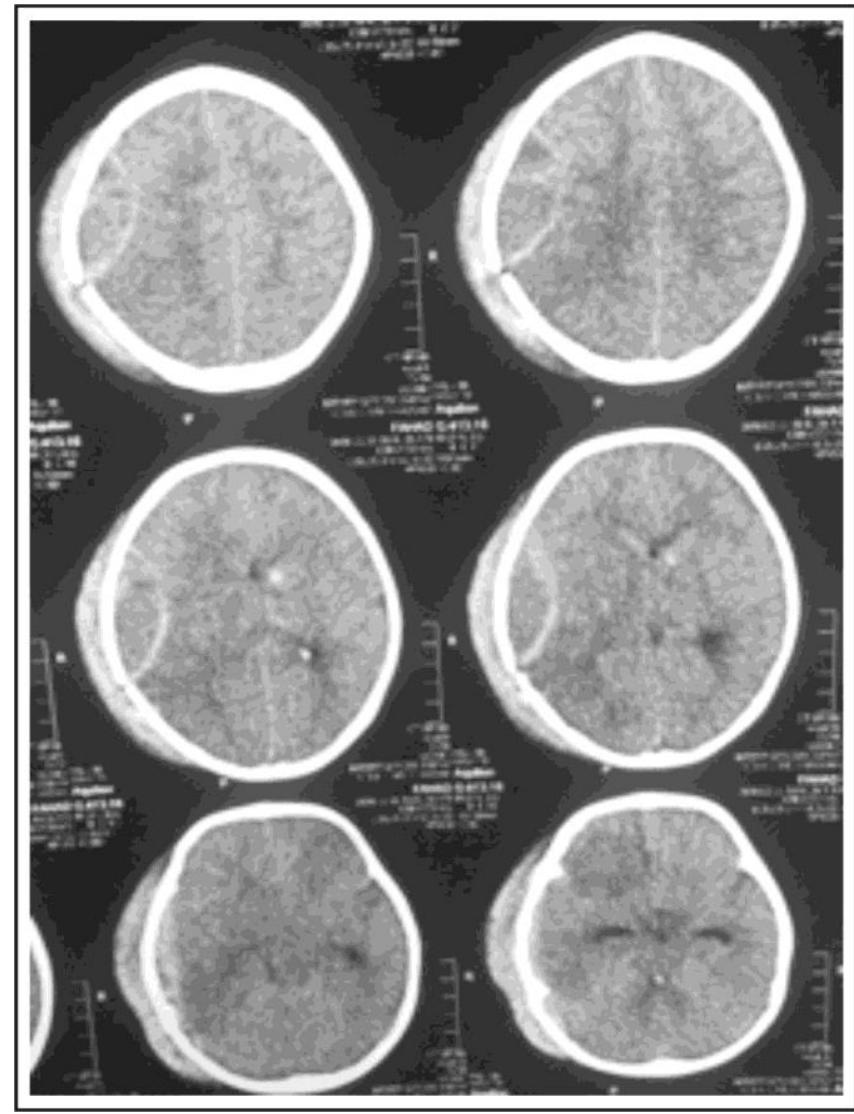

Figure 1: Axial CT brain of the patient showing right-sided isodense epidural hematoma. There is a midline shift to the left side of about $3 \mathrm{~mm}$. Overlying subgaleal hematoma. (Used with the patient's consent)

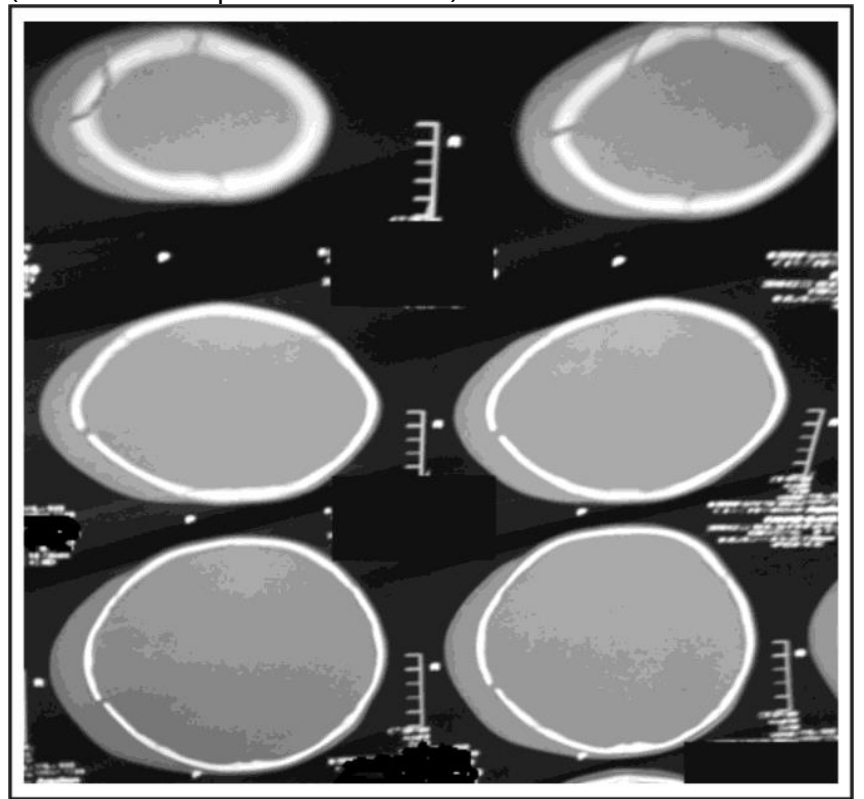

Figure 2: CT scan of the same patient showing a linear skull fracture on the right side. (Used with the patient's consent) 
$25 \mathrm{ml}$ of acute hematoma was evacuated (Figure 3).

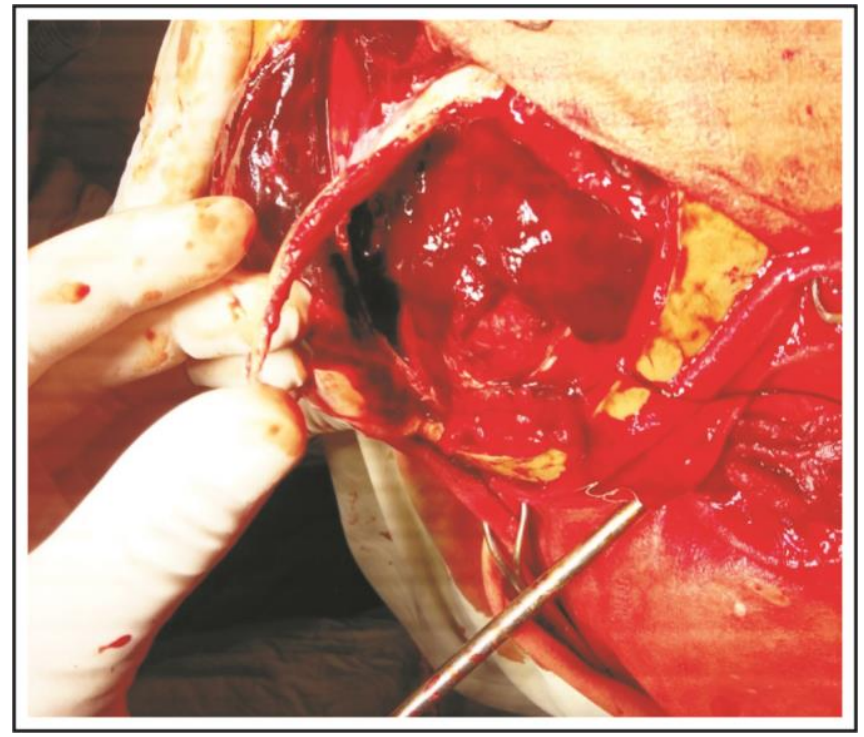

Figure 3: Peroperative picture of the hematoma (used with patient's permission).

Postoperatively, the patient made a good recovery and was discharged on the $5^{\text {th }}$ postoperative day with a Glasgow outcome score "GOS" of 4.

\section{DISCUSSION}

Brain CT is consistently the most preferred diagnostic modality to assess head injuries, especially for intracranial hemorrhage. ${ }^{5}$ CT scan results vary in different tissues according to their densities. Attenuation of CT X-ray is proportional to the density of the tissue. Tissue having low densities like air and water have little attenuation lookshypodense, while tissues with a high density such as bones having high attenuation appear bright in $\mathrm{CT}^{6}{ }^{6}$ The radiodensity of tissue is measured using Hounsfield (a quantitative scale) ${ }^{7}$. Attenuation of CT X-rays is expressed according to linear density scale as "Hounsfield unit" $(\mathrm{HU})^{8}$. The HU value of water is " 0 " with which the HU values for all other CT contents are computed accordingly:

$$
\mathrm{HU}=\frac{1000 \times(\mu \text { tissue }-\mu \mathrm{H} 2 \mathrm{O})}{\mu \mathrm{H} 2 \mathrm{O}}
$$

$\mu$ represents $C T$ linear attenuation coefficient.

Value of HU varies from -1000 (Air) to more than +1000 (Bone), HU values of different tissues found on CT head are given in (Table 1). ${ }^{9}$

Table 1: HU Values for Different Tissue Contents on Head CT.

\begin{tabular}{lc} 
Tissues & Hounsfield Units \\
Bone & 1000 \\
Hemorrhage & 65 to 95 \\
Gray matter & 30 to 40 \\
Muscle & 20 to 40 \\
White matter & 20 to 30 \\
Water (CSF) & 0 \\
Fat & -30 to -70 \\
Air & -1000 \\
\hline
\end{tabular}

There is a direct relation between attenuation level and hemoglobin. The more blood is saturated with Iron and Hemoglobin the more will be its density and high attenuation level and will appear brighter over CT scan. ${ }^{10}$ Normally blood clot is hyperdense (acute blood 30-80 HU). The shape of subdural hematomas has concave presentation on brain $\mathrm{CT}$ while the epidural is convex towards the brain. The density of hematoma increases as blood clots due to expulsion of plasma and close packing of solid components. ${ }^{11}$ Isodense radiological presentation of epidural hematoma is rarely found.A study of 151 patients didn't report even a single isodense epidural hematoma. ${ }^{12}$ Direct relation has been demonstrated between $\mathrm{CT}$ attenuation value and HCT level Reference. The difference in densities of hematoma is related to the concentration of erythrocytes and hemoglobin proteins concentration. Hemoglobin concentration of 9 to $11{\mathrm{~g} . \mathrm{dl}^{-1}}^{-}$, shows almost the same density on brain CT scan. ${ }^{4}$

In the current case, there was no dural laceration thus no mixing of CSF with blood. 
Therefore, we concluded that isodense presentation on brain CT is due to a low concentration of erythrocytes as the patient was anemic.

\section{Consent}

This case study is reported with the permission of the patient's parent.

\section{REFERENCES}

1. Urban JE, Whitlow CT, Edgerton CA, Powers AK, Maldjian JA, Stitzel JD. Motor Vehicle CrashRelated Subdural Hematoma from Real-World Head Impact Data. J Neurotrauma, 2012; 29 (18): 2774-2781.

2. Kurland D, Hong C, Aarabi B, Gerzanich V, Simard JM. Hemorrhagic Progression of a Contusion after Traumatic Brain Injury: A Review. J Neurotrauma, 2012; 29 (1): 19-31.

3. Mendonca R, Lima TTF, Dini LI, Krebs CLL. Bilateral Isodense Epidural Hematoma Case report. Arq Neuropsiquiatr. 2005; 63 (3-B): 862-863.

4. Lobato RD, Gomez PA, Nunez AP, Arrese I. Hyperacute epidural haematoma isodense with the brain on computed tomography. Acta Neurochir (Wien), 2004; 146 (2): 193-194.

5. Heit JJ, IV $M$, Wintermark $M$. Imaging of
Intracranial Hemorrhage. J Stroke, 2017; 19 (1): 1127.

6. Computed Tomography (CT) of the Brain. https://case.edu/med/neurology/NR/CT Basics.htm. Accessed March 25, 2021.

7. Broder J, Preston R. Imaging the Head and Brain. In: Diagnostic Imaging for the Emergency Physician. Elsevier; 2011: 1-45.

8. Lev MH, Gonzalez RG. CT Angiography and CT Perfusion Imaging. In: Brain Mapping: The Methods. Elsevier; 2002: 427-484.

9. Lufkin RB, Hanafee W. Magnetic resonance imaging of head and neck tumors. CANCER METASTASIS Rev. 1988; 7(1): 19-38.

10. Bruni SG, Patafio FM, Dufton JA, Nolan RL, Islam O. The Assessment of Anemia from Attenuation Values of Cranial Venous Drainage on Unenhanced Computed Tomography of the Head. Can Assoc Radiol J. 2013; 64 (1): 46-50.

11. Hara T, Matoba N, Zhou $X$, et al. Automated detection of extradural and subdural hematoma for contrast-enhanced $C T$ images in emergency medical care. In: Giger ML, Karssemeijer N, eds. Medical Imaging 2007: Computer-Aided Diagnosis, 2007; 6514: 651432.

12. Tapiero B, Richer E, Laurent F, Guibert-Tranier F, Caillé JM. Post-traumatic extradural haematomas. CT diagnosis and features. J Neuroradiol. 1984; 11 (3): 213-226.

https://europepmc.org/article/med/6512598.

Accessed March 25, 2021.

\section{Additional Information}

Disclosures: Authors report no conflict of interest.

Ethical Review Board Approval: The study was conformed to the ethical review board requirements.

Human Subjects: Consent was obtained by the patient included in this study.

Conflicts of Interest:

In compliance with the ICMJE uniform disclosure form, all authors declare the following:

Financial Relationships: All authors have declared that they have no financial relationships at present or within the previous three years with any organizations that might have an interest in the submitted work.

Other Relationships: All authors have declared that there are no other relationships or activities that could appear to have influenced the submitted work. 


\section{AUTHORS CONTRIBUTIONS}

\begin{tabular}{|l|l|l|}
\hline Sr.\# & Author's Full Name & Intellectual Contribution to Paper in Terms of: \\
\hline 1. & Musawer Khan & Study Design and Methodology. \\
\hline 2. & Sajid Khan & Paper Writing, Referencing, Data Calculations and \\
\hline 3. & Sajid Khan & Data Collection and Calculations. \\
\hline 4. & Naeem-ul-Haq & Analysis of Data and Interpretation of Results etc. \\
\hline 5. & Muhammad Ishaq & Literature Review and Manuscript Writing. \\
\hline 6. & Mumtaz Ali & Quality Insurer. \\
\hline
\end{tabular}

